University of Wollongong

Research Online

Faculty of Social Sciences - Papers (Archive) Faculty of Arts, Social Sciences \& Humanities

$1-1-2017$

Societal and personal concerns, their associations with stress, and the implications for progress and the future

\author{
Melanie J. Randle \\ University of Wollongong, mrandle@uow.edu.au \\ Richard Eckersley \\ Australia21 Ltd \\ Leonie M. Miller \\ University of Wollongong, leoniem@uow.edu.au
}

Follow this and additional works at: https://ro.uow.edu.au/sspapers

Part of the Education Commons, and the Social and Behavioral Sciences Commons

Research Online is the open access institutional repository for the University of Wollongong. For further information contact the UOW Library: research-pubs@uow.edu.au 


\title{
Societal and personal concerns, their associations with stress, and the implications for progress and the future
}

\begin{abstract}
A survey of more than 2000 people in four countries examined levels of concern across 19 personal and 23 societal issues. On average, $49 \%$ were moderately or seriously concerned about the personal issues, with health, wellbeing and financial concerns topping the ranking. Country differences were small, but generational differences were substantial. An average of $58 \%$ of Generation Y were moderately or seriously concerned, compared to $35 \%$ of Pre-boomers, with significant differences for 14 of the 19 issues. In terms of societal issues, an average of $41 \%$ were moderately or seriously concerned, with social and moral issues ranking ahead of economic and environmental matters. Americans were the most concerned with societal issues and Australians the least. Societal concerns increased with age. Both sets of concerns, but especially personal, were predictors of perceived personal stress, although specific concerns were both positively and negatively associated with stress. The ranking of societal concerns, country differences, age differences, and the relationship between concerns and stress are discussed. Findings provide insights into the relationships between social conditions, personal circumstances and wellbeing, supporting an argument that researchers need to pay more attention to the "psychosocial dynamics" of contemporary life in assessing human progress as a pathway to the future.

\section{Disciplines}

Education | Social and Behavioral Sciences

\section{Publication Details}

Randle, M., Eckersley, R. \& Miller, L. (2017). Societal and personal concerns, their associations with stress, and the implications for progress and the future. Futures, 93 68-79.
\end{abstract}




\title{
Societal and personal concerns, their associations with stress, and the implications for progress
}

\author{
and the future
}

Melanie Randle ${ }^{1}$, Richard Eckersley ${ }^{2}$ and Leonie Miller $^{3}$

\begin{abstract}
${ }^{1}$ Australian Health Services Research Institute, School of Management, Operations and Marketing, Faculty of Business, University of Wollongong, Northfields Ave, Wollongong NSW 2500 Australia. mrandle@uow.edu.au.
\end{abstract}

${ }^{2}$ Australia21 Ltd, 23 Garland Rd, Bundanoon, NSW 5278, Australia. richard@ richardeckersley.com.au

${ }^{3}$ School of Psychology, Faculty of Social Sciences, University of Wollongong, Northfields Ave, Wollongong NSW 2500 Australia. leoniem@uow.edu.au.

*Correspondence should be addressed to Melanie Randle, University of Wollongong, Northfields Ave, Wollongong, NSW 2522, Australia (e-mail: mrandle@uow.edu.au).

\begin{abstract}
A survey of more than 2,000 people in four countries examined levels of concern across 19 personal and 23 societal issues. On average, $49 \%$ were moderately or seriously concerned about the personal issues, with health, wellbeing and financial concerns topping the ranking. Country differences were small, but generational differences were substantial. An average of $58 \%$ of Generation Y were moderately or seriously concerned, compared to $35 \%$ of Pre-boomers, with significant differences for 14 of the 19 issues. In terms of societal issues, an average of $41 \%$ were moderately or seriously concerned, with social and moral issues ranking ahead of economic and environmental matters. Americans were the most concerned with societal issues and Australians the least. Societal concerns increased with age. Both sets of concerns, but especially personal, were predictors of perceived personal stress, although specific concerns were both positively and negatively associated with stress. The ranking of societal concerns, country differences, age differences, and the relationship between concerns and stress are discussed. Findings provide insights into the relationships between social conditions, personal circumstances and wellbeing, supporting an argument that researchers need to pay more attention to the "psychosocial dynamics" of contemporary life in assessing human progress as a pathway to the future.
\end{abstract}

Keywords: futures, personal concerns, societal concerns, psychological stress, wellbeing

Citation:

\section{Introduction}

We measure human progress and development by how well we are doing relative to the past on a range of indicators of quality of life and wellbeing. Concepts and measures of progress are also how we map a course towards the future. There are complex, dynamic, often reciprocal relationships 
between quality of life and wellbeing, contemporary social conditions, progress and the future (Author 2005, pp.185-201; 2016).

In these relationships, perceptions matter. Perceptions of our lives today affect our wellbeing and how we see the future, in terms of both what we expect and what we wish for - interpretations of the present world can set boundaries on what is considered possible tomorrow and what outcomes are more likely. Visions of the future can impact on contemporary society through qualities such as social cohesion, optimism and confidence, and on personal wellbeing through their effects on qualities such as hope, belonging, purpose, and meaning in life. Wellbeing can shape present social conditions and our ability to shape the future and meet its challenges through its impact on critical factors such as morale, vitality and resilience.

In other words, quality of life and progress are functions of how people feel about their lives as well as the material conditions in which they live. Traditionally the research and policy focus has been on objective indicators, such as standard of living measured as per capita income, life expectancy, and education (which make up the Human Development Index) (Author 2016). In the past two decades researchers, statistical agencies, and policy analysts have become more interested in broader and better measures, notably the subjective dimension of quality of life and progress (Author 2009, 2016). Most attention has focused on people's "subjective wellbeing", commonly measured as self-reported life satisfaction or happiness.

Measures of subjective wellbeing do not fundamentally alter the dominant view of quality of life, and so of human progress, which is broadly equated with modernisation (Author 2016). A recent paper notes that "there appears to be an emerging consensus in the policy community that subjective wellbeing ought to be the key criterion of policy success" (Zagorski et al. 2014, p. 1107).

However, there are some streams of evidence that expose the limitations of subjective-wellbeing indicators, and cast doubt on how we currently conceptualise and measure progress. Some of this evidence emerges from different, and wider, measures of personal wellbeing (Author 2009, 2011, 2016).

Other research that challenges the legitimacy - or at least the completeness - of subjective-wellbeing measures people's perceptions of population or societal wellbeing or quality of life. This social focus has attracted much less attention than subjective wellbeing, with some researchers disregarding the social perspective because it is at odds with the objective data and subjective wellbeing. The two perspectives can be very different: the personal is largely positive and optimistic, the societal more negative and pessimistic (Author 2000a; 2000b; 2009; 2016; Steenvoorden 2015).

One way of tapping into people's perceptions of life, both personal and societal, is to ask about their level of satisfaction or concern about a range of issues or priorities, covering both personal and societal issues. These surveys are often carried out by social research organisations, and are not usually integrated into general assessments of quality of life, progress or the future; more often they feed into contemporary political debates (e.g. Edelman Intelligence 2017; Ipsos Social Research Institute 2015; Ipsos MORI 2017; Pew Research Center 2015).

An important way in which perceptions of life can influence quality of life is through psychological stress, which has been found to predict wellbeing in studies of the general population, specific populations and across different countries (Firth-Cozens 2003; Wiklund et al. 2012; Rowlands et al. 2015). Research shows that levels of stress and stress-related illness increase when people feel that their stress is a result of worsening circumstances, they have little control over its causes, and do not know how long it is going to last (Sapolsky 2005).

This study examines people's levels of concern with a range of societal and personal issues characterising modern life (but often having a futures orientation), and their associations with personal stress, in four countries - the US, UK, Canada and Australia. A companion paper, based on 
other data collected in the same survey, explored people's ratings of future threats to humanity, and their associations with these contemporary concerns and personal stress (Authors 2015).

For the purposes of the present study, quality of life is defined as the degree to which people enjoy living conditions (social, economic, cultural and environmental) that are conducive to total wellbeing (physical, mental, social and spiritual). Progress, by which we chart humanity's journey from the past and towards the future, is defined as improving quality of life. Important to assessing both quality of life and progress are the "psychosocial dynamics" of modern life: the complex interactions and relationships between the subjective and objective worlds, between social conditions and individual psychology and behaviour (Author 2009; 2016).

Specifically, the aims of this study were to:

1. Explore the issues that are of most concern to people at the moment

2. Understand whether people are more concerned with personal or societal issues

3. Examine what impact concern about different issues has on perceived personal stress

4. Identify whether differences exist between (i) countries and (ii) generations.

While this study is not located, at first glance, within the discipline of futures studies, the findings are relevant to futures research, especially in terms of elucidating the subjectivity and complexity of the subject, as noted above and elaborated on later. This work is a product of cross-disciplinary research involving input from psychology and transdisciplinary analysis of human progress and wellbeing.

\section{Materials and methods}

\subsection{Fieldwork}

Fieldwork was conducted in January-February 2013 drawing participants from international online research panel Survey Sampling International. The panel includes members from 86 countries worldwide and samples are periodically independently validated to ensure representativity and consistency (Survey Sampling International 2016). While the validity of online survey data has been questioned in the past, empirical research has demonstrated that online survey samples do not differ from census population statistics to a greater extent than paper surveys (although the deviation differs in nature) and there are also no significant differences in terms of data contamination due to response styles (Dolnicar et al. 2009). Furthermore, online surveys have the added advantages of having lower dropout rates and producing more complete data than paper surveys (Dolnicar et al. 2009), and the ability to collect data in multiple countries simultaneously in a relatively short timeframe and low cost.

Representative samples of panel members in the United States, United Kingdom, Canada and Australia were sent invitations to complete the survey which was open for just over two weeks until a minimum number of 500 completions per country had been achieved. Panel members received points for completing the survey which could then be used to purchase a range of products and services online. The questions used to conduct the present investigation focused on personal and societal concerns and perceived personal stress, and were part of a larger survey that included a range of topics of general interest. Other, related questions on the perceived probability of future threats to humanity and levels of agreement with six statements reflecting possible responses to these perceptions are addressed in a separate companion paper (Authors 2015). The research protocol was reviewed and approved by the University's Human Research Ethics Committee.

\subsection{Sample}


Participants included citizens and permanent residents of each of the four countries who were over the age of 18. A minimum of 500 participants per country produced the overall sample size of 2,073, and quotas were used to ensure each country sample was representative for age, sex and area of residence. Thus each sample provides a normalised profile of each country's citizens (therefore avoiding the need for weighting to adjust for lack of representation). Given that a key part of this investigation was to examine differences between countries, it was important to adopt a sampling method that provided all countries with parity in the analysis (it was determined that weighting by country population would have diluted the importance of borders in assessing the international perspective and would therefore have been less meaningful). A sample of 500 for each country was considered sufficient to yield adequate statistical power for any effects of note.

\subsection{Measures}

Personal concerns. Personal concerns were measured by showing participants a list of 19 issues and asking "Thinking about your own personal future, how concerned are you about each of the following?". The list of items was initially based on those identified by (Lindfors et al. 2012) and then extended to include issues relevant to a range of different age groups that related to family/relationships (family relationships, wellbeing of family members, friendships), health/ageing (physical health, mental/emotional health, death, serious accidents, old age), work/education (education, finding a job, finding a job I like, retirement), finance (financial security, superannuation, cost of living) and emotions (failure/disappointment, making wrong decisions, loneliness, emptiness). Participants indicated their level of concern using a four point scale labelled "Seriously concerned", "Moderately concerned", A little bit concerned" and "Not at all concerned". Items were randomly ordered and the online format ensured that all questions were answered before proceeding to the next question.

Societal concerns. Societal concerns were measured by asking participants: "In your everyday life, how concerned do you feel about the following issues?", and presenting them with a list of 23 issues. The orientation of this question was different to the wording of the question regarding personal concerns because each was customised to reflect the context in which people might experience these types of concerns (as revealed by the measures development process which included qualitative interviews and pilot testing). Most commonly, societal concerns were expressed in terms of their impact on individuals' everyday lives. In contrast, personal concerns were expressed in terms of an individual's own future. The questions were therefore developed and worded to best align with the typical frame of experience.

The list of societal concerns was developed to reflect the wide range of issues currently facing society as a whole, and included technological issues (online terrorism/warfare, increasing lack of privacy, technological changes e.g. internet/social networking, online bullying), economic issues (collapse of global financial systems, long-term economic depression), political issues (the state of world politics, corruption of politicians/officials, the state of politics in my country, wars/weapons of mass destruction, terrorist attacks, crime and violence in everyday life), ecological issues (global warming/climate change, lack of fresh water, resources such as oil running out, pollution of air and water, natural disasters e.g. tsunamis /earthquakes/wildfires etc.), humanitarian/health issues (famine and poverty, existing incurable diseases e.g. cancer, new types of incurable diseases, worldwide epidemics/pandemics/outbreaks) and social/moral issues (breakdown of society's moral values, how fast society is changing e.g. divorce rates/birth rates/household changes). Participants could indicate their concern on a five-point scale labelled "I'm seriously concerned", "I'm moderately concerned", "I'm a little bit concerned", "I think about it but I'm not at all concerned" and "I never think about it". The final response category ("I never think about it") was added after pre-testing revealed that some respondents had difficulty indicating a level of concern for issues that they never thought about in their everyday lives. The same issue was not found in pre-testing the question on personal concerns, possibly because of the greater degree of self-reference contained in it; accordingly the "I never think about it" response category was omitted for personal concerns. The 23 societal concerns were 
randomly ordered to avoid order bias. For each societal concern, participants were also asked to indicate how often they thought about each issue using a five-point answer scale labelled "Never", "Very occasionally", "At least once a month", "At least once a week" and "It's always on my mind". Again, the 23 items for this question were randomly ordered.

Perceived stress. Perceived Stress was measured using the 14-item Perceived Stress Scale (PSS, Cohen 1983). Participants were presented with a list of 14 potentially stressful or non-stressful occurrences and asked to indicate how often they had experienced each during the last month on a five-point scale labelled "Very often", "Fairly often", "Sometimes", "Almost never" and "Never". Seven items were negatively framed to reflect stressful occurrences (e.g. been upset because of something that happened, found that you could not cope with all the things that you had to do, felt difficulties were piling up so high that you could not overcome them, felt nervous and stressed). The other seven items were positive framed to reflect non-stressful situations (e.g. felt confident about your ability to handle your personal problems, felt that you were on top of things, felt that you were effectively coping with important changes that were occurring in your life). Scores for all items (including the seven with reverse scoring) were summed to produce an overall score of perceived stress for each individual (range 0-56). Items were randomly ordered to minimise order bias. The internal consistency of the scale with this sample was very good (Cronbach's $\alpha=.87$ ).

Socio-demographic characteristics. For the purposes of screening, describing the sample and identifying differences between groups of interest, participants were asked questions regarding their socio-demographic characteristics. These included age, sex, income, education, employment status and position, relationship and family status. For the purposes of comparing different age groupings, individuals were categorised according to generational groups (Mackay 1997). These are somewhat arbitrary and the birth years for different generations can differ by several years, but generally span about 15 years (Mackay 1997, pp.1-4). In this study, individuals born in 1945 or earlier were termed the "Pre-boomers" $(\mathrm{n}=181)$, individuals born from 1946-1961 were termed the "Baby boomers" $(\mathrm{n}=654)$, those born from 1962-1977 were termed "Generation X" (Gen X, $n=628)$ and those born from 1978-1994 were termed "Generation Y" (Gen Y, n=610).

\section{Analysis and results}

\subsection{Sample characteristics}

The sample of 2,073 participants included 518 from the US, 519 from the UK, 520 from Canada and 516 from Australia. Just over half (52\%) of participants were female, and the age distribution reflected the population distributions of the different countries included (overall, 12\% were aged 18$24,17 \%$ were $25-34,20 \%$ were $35-44,19 \%$ were $45-54,21 \%$ were $55-64$ and $12 \%$ were aged 65 or over). Just under one third had attended secondary school (31\%), $28 \%$ had attained some form of technical or vocational training and $37 \%$ had a university qualification. In terms of employment, the largest proportion (37\%) were employed full time, 16\% were employed part time or casually, nine percent were unemployed but looking for work and the remainder were not looking for work (including those who are retired, studying, homemakers and so on). Just under half of the sample $(46 \%)$ were married, $22 \%$ were in a relationship or living with someone and the remaining $32 \%$ were not in a relationship.

\subsection{Personal concerns}

Overall, across the four countries and for the 19 personal issues included in the survey, an average of $25 \%$ said that they were "not at all concerned", $27 \%$ were "a little bit concerned", $27 \%$ were "moderately concerned", and $21 \%$ were "seriously concerned". On average, people were most likely to be seriously concerned about the cost of living (38\%), wellbeing of family members (36\%), financial security $(36 \%)$ and their physical health $(27 \%)$. They were most likely to report being not at 
all concerned about finding a job (41\%), education (39\%), finding a job they like (38\%) and superannuation (38\%). Regarding the number of people who indicated they were either moderately or seriously concerned about each issue (which on average was $49 \%$ of the population), health, wellbeing and financial concerns topped the ranking, with 74\% concerned about both the wellbeing of family members and the cost of living.

Chi-square tests on frequency data of the entire samples were performed to test for significant differences between country and generational groups. Note that Bonferroni correction has not been applied, however a conservative significance criterion has been set in these tests $(p=\leq 0.001)$. Power analysis indicated that these analyses were suitably powered for small effect sizes ( $G^{*}$ Power: Faul et al. 2007). The percentage of the population either moderately or seriously concerned about each personal issue by country and generation is shown in Table 1 , and $p$-values for the Chi-square tests are also shown. Significant differences were found between countries for only three issues, with Australians and British being less concerned about financial security and retirement, but Australians more likely to be concerned about their superannuation. 
Table 1: Percentage "moderately concerned" or "seriously concerned" about each personal issue by country and generation.

\begin{tabular}{|c|c|c|c|c|c|c|c|c|c|c|c|}
\hline \multicolumn{12}{|c|}{ Percentage who are moderately or seriously concerned } \\
\hline \multirow[b]{2}{*}{ Personal issue } & \multirow[b]{2}{*}{$\begin{array}{c}\text { Total } \\
\text { sample } \\
(\%)\end{array}$} & \multicolumn{5}{|c|}{ COUNTRY } & \multicolumn{5}{|c|}{ GENERATION } \\
\hline & & $\begin{array}{c}\text { Australia } \\
(n=516)\end{array}$ & $\begin{array}{l}\text { Canada } \\
(n=520)\end{array}$ & $\begin{array}{c}\text { UK } \\
(n=519)\end{array}$ & $\begin{array}{c}\text { USA } \\
(n=518)\end{array}$ & $p^{\dagger}$ & $\begin{array}{c}\text { Gen Y } \\
(n=610)\end{array}$ & $\begin{array}{c}\text { Gen X } \\
(n=628)\end{array}$ & $\begin{array}{c}\text { Baby } \\
\text { boomers } \\
(n=654)\end{array}$ & $\begin{array}{c}\text { Pre- } \\
\text { boomers } \\
(n=181)\end{array}$ & $p^{*}$ \\
\hline Wellbeing of family members & 73.6 & 70.3 & 75.4 & 72.6 & 75.9 & .153 & 75.9 & 73.4 & 71.9 & 72.4 & .420 \\
\hline Cost of living & 73.6 & 70.5 & 75.2 & 74.8 & 73.9 & .314 & 76.2 & 75.6 & 71.9 & 64.1 & .005 \\
\hline Financial security & 67.9 & 62.6 & 73.3 & 65.5 & 70.3 & $.001 *$ & 72.1 & 70.5 & 66.2 & 50.8 & $<.001 *$ \\
\hline Physical health & 64.0 & 62.6 & 66.5 & 61.3 & 65.6 & .243 & 63.9 & 61.8 & 66.7 & 62.4 & .314 \\
\hline Family relationships & 51.0 & 51.0 & 51.0 & 47.2 & 55.0 & .096 & 63.0 & 52.4 & 41.1 & 42.0 & $<.001 *$ \\
\hline Mental/emotional health & 50.8 & 49.6 & 54.4 & 51.8 & 47.5 & .138 & 59.8 & 50.5 & 46.0 & 39.2 & $<.001 *$ \\
\hline Old age & 49.5 & 44.8 & 51.5 & 50.3 & 51.4 & .097 & 48.5 & 48.2 & 52.8 & 45.3 & .198 \\
\hline Retirement & 47.5 & 38.6 & 52.3 & 44.9 & 54.1 & $<.001 *$ & 45.6 & 53.7 & 48.9 & 27.1 & $<.001 *$ \\
\hline Making wrong decisions & 46.6 & 42.4 & 47.5 & 44.7 & 51.7 & .019 & 58.0 & 47.3 & 39.9 & 29.8 & $<.001 *$ \\
\hline Finding a job I like & 44.5 & 39.5 & 47.1 & 44.5 & 46.7 & .054 & 67.0 & 51.3 & 28.0 & 4.4 & $<.001 *$ \\
\hline Friendships & 43.5 & 40.9 & 46.2 & 42.6 & 44.2 & .362 & 56.6 & 41.6 & 35.3 & 35.4 & $<.001 *$ \\
\hline Serious accidents & 43.1 & 40.1 & 45.8 & 41.4 & 45.0 & .193 & 53.4 & 39.0 & 39.6 & 34.8 & $<.001 *$ \\
\hline Death & 41.9 & 35.9 & 42.9 & 45.3 & 43.6 & .012 & 48.2 & 42.4 & 38.5 & 31.5 & $<.001 *$ \\
\hline Failure/disappointment & 41.6 & 38.6 & 40.2 & 41.8 & 45.9 & .093 & 58.0 & 41.9 & 30.6 & 25.4 & $<.001 *$ \\
\hline Finding a job & 40.8 & 36.8 & 41.0 & 40.5 & 44.8 & .078 & 63.8 & 42.7 & 27.4 & 5.0 & $<.001 *$ \\
\hline Loneliness & 40.5 & 37.4 & 41.0 & 43.5 & 40.2 & .249 & 53.0 & 38.4 & 34.7 & 27.1 & $<.001 *$ \\
\hline Education & 37.3 & 37.4 & 39.2 & 34.5 & 38.2 & .428 & 54.8 & 40.0 & 23.7 & 18.8 & $<.001 *$ \\
\hline Emptiness & 37.0 & 34.3 & 36.0 & 40.8 & 36.7 & .160 & 50.0 & 33.4 & 32.0 & 23.2 & $<.001 *$ \\
\hline Superannuation & 30.6 & 41.9 & 25.6 & 28.3 & 26.6 & $<.001 *$ & 34.6 & 29.8 & 30.1 & 21.5 & $<.001 *$ \\
\hline Average across all concerns & 48.7 & 46.1 & 50.1 & 48.2 & 50.4 & & 58.0 & 49.2 & 43.4 & 34.7 & .008 \\
\hline
\end{tabular}

$* p \leq 0.001$.

${ }^{\dagger} p$-values of Chi-square tests of homogeneity across country samples. ${ }^{\ddagger} p$-values of Chi-square tests of independence across generational groups. 
Generally speaking, degree of concern about personal issues declined with age. Significant differences were found between generations for 14 of the 19 personal issues (Table 1). Generation Y was the generation most likely to express concern for 13 of these, including financial security $(72 \%)$, finding a job (64\%) and finding a job they like (67\%), family relationships (63\%), mental/emotional health (60\%), making wrong decisions (58\%), failure and disappointment (58\%), friendships (57\%), education (55\%), serious accidents (53\%), loneliness (53\%), emptiness (50\%) and death (48\%). The exception was retirement, about which Generation X expressed the most concern (54\%).

\subsection{Societal concerns}

On average, people were most likely to be seriously concerned about crime and violence (26\%), national politics $(23 \%)$, corruption of politicians and officials $(22 \%)$ and breakdown of society's moral values (22\%). The proportions of each country and generation who were moderately or seriously concerned about each societal issue are shown in Table 2. 
Table 2: Percentage "moderately or "seriously" concerned about each societal issue by country and generation.

\begin{tabular}{|c|c|c|c|c|c|c|c|c|c|c|c|}
\hline \multicolumn{12}{|c|}{ Percentage who are moderately or seriously concerned } \\
\hline \multirow[b]{2}{*}{ Societal issue } & \multirow[b]{2}{*}{$\begin{array}{c}\text { Total } \\
\text { sample } \\
(\%)\end{array}$} & \multicolumn{5}{|c|}{ COUNTRY } & \multicolumn{5}{|c|}{ GENERATION } \\
\hline & & $\begin{array}{c}\text { Australia } \\
(\mathrm{n}=516)\end{array}$ & $\begin{array}{c}\text { Canada } \\
(\mathrm{n}=520)\end{array}$ & $\underset{(\mathrm{n}=519)}{\mathrm{UK}}$ & $\begin{array}{c}\text { USA } \\
(\mathrm{n}=518)\end{array}$ & $p^{\dagger}$ & $\begin{array}{c}\text { Gen Y } \\
(\mathrm{n}=610)\end{array}$ & $\begin{array}{c}\text { Gen X } \\
(\mathrm{n}=628)\end{array}$ & $\begin{array}{c}\text { Baby } \\
\text { boomers } \\
(\mathrm{n}=654)\end{array}$ & $\begin{array}{c}\text { Pre- } \\
\text { boomers } \\
(\mathrm{n}=181)\end{array}$ & $p^{*}$ \\
\hline Crime and violence in everyday life & 58.4 & 58.9 & 56.3 & 54.1 & 64.3 & .007 & 52.6 & 55.4 & 63.8 & 69.1 & $<.001 *$ \\
\hline The state of politics in my country & 52.1 & 48.3 & 41.9 & 52.6 & 65.4 & $<.001^{*}$ & 43.1 & 47.0 & 59.2 & 74.0 & $<.001^{*}$ \\
\hline Breakdown of society's moral values & 50.2 & 52.5 & 46.9 & 44.9 & 56.4 & $.001 *$ & 45.6 & 47.1 & 54.3 & 61.3 & $<.001^{*}$ \\
\hline Existing incurable diseases & 49.2 & 46.3 & 50.8 & 49.5 & 50.2 & .484 & 48.9 & 46.7 & 51.1 & 52.5 & .340 \\
\hline Corruption of politicians/officials & 48.6 & 38.8 & 46.5 & 44.9 & 64.3 & $<.001 *$ & 40.7 & 43.9 & 54.3 & 71.3 & $<.001^{*}$ \\
\hline Increasing lack of privacy & 45.8 & 43.2 & 46.5 & 40.3 & 53.1 & $<.001 *$ & 44.3 & 45.9 & 47.9 & 43.1 & .525 \\
\hline Pollution of air and water & 44.4 & 43.0 & 52.5 & 34.3 & 47.7 & $<.001 *$ & 41.6 & 43.2 & 45.9 & 52.5 & .054 \\
\hline Long-term economic depression & 44.4 & 35.5 & 37.9 & 47.8 & 56.6 & $<.001^{*}$ & 41.6 & 44.1 & 47.1 & 45.3 & .274 \\
\hline The state of world politics & 44.0 & 36.8 & 39.8 & 41.6 & 57.7 & $<.001^{*}$ & 36.4 & 40.0 & 49.7 & 63.0 & $<.001 *$ \\
\hline Global warming/climate change & 43.6 & 42.2 & 46.5 & 38 & 47.5 & .007 & 41.6 & 42.7 & 44.5 & 49.7 & .246 \\
\hline Collapse of global financial systems & 42.0 & 34.5 & 39.6 & 41.8 & 52.1 & $<.001^{*}$ & 37.9 & 40.1 & 44.6 & 53.0 & $.001 *$ \\
\hline Natural disasters & 39.3 & 42.6 & 38.1 & 32.9 & 43.6 & $.001 *$ & 37.4 & 36.9 & 42.2 & 43.6 & .105 \\
\hline Famine and poverty & 39.3 & 36.2 & 42.9 & 35.6 & 42.5 & .019 & 39.5 & 34.1 & 42.4 & 45.9 & .005 \\
\hline How fast society is changing & 38.8 & 36.8 & 36.5 & 35.5 & 46.5 & $<.001 *$ & 38.2 & 38.2 & 39.1 & 42.0 & .804 \\
\hline Terrorist attacks & 36.8 & 31.8 & 31.9 & 40.5 & 43.1 & $<.001 *$ & 34.4 & 33.6 & 39.8 & 45.3 & .006 \\
\hline Wars/weapons of mass destruction & 35.6 & 28.9 & 33.8 & 35.3 & 44.6 & $<.001 *$ & 33.1 & 30.3 & 39.3 & 49.7 & $<.001^{*}$ \\
\hline Lack of fresh water & 34.0 & 34.5 & 39.8 & 24.7 & 36.9 & $<.001 *$ & 32.6 & 31.7 & 36.2 & 38.1 & .184 \\
\hline New types of incurable diseases & 33.9 & 28.1 & 36.3 & 31.8 & 39.2 & $.001 *$ & 35.2 & 31.8 & 34.6 & 33.7 & .614 \\
\hline Technological changes & 32.2 & 30.0 & 35.2 & 27.0 & 36.7 & .002 & 35.4 & 33.1 & 30.4 & 24.9 & .036 \\
\hline Resources such as oil running out & 32.1 & 28.1 & 30.6 & 34.1 & 35.5 & .044 & 33.8 & 27.7 & 34.1 & 34.3 & .048 \\
\hline Worldwide epidemics & 31.7 & 27.9 & 33.7 & 27.2 & 38.0 & $<.001 *$ & 32.8 & 29.5 & 31.7 & 35.9 & .351 \\
\hline Online bullying & 30.6 & 31.2 & 37.3 & 25.0 & 28.8 & $<.001 *$ & 32.8 & 31.4 & 27.4 & 32.0 & .176 \\
\hline Online terrorism/warfare & 28.8 & 24.0 & 26.0 & 28.9 & 36.1 & $<.001 *$ & 26.6 & 25.2 & 30.7 & 41.4 & $<.001^{*}$ \\
\hline Average across all concerns & 40.7 & 37.4 & 40.3 & 37.8 & 47.3 & & 38.5 & 38.2 & 43.1 & 47.9 & \\
\hline
\end{tabular}

$* p \leq 0.001$

${ }^{\dagger} p$-values of Chi-square tests of homogeneity across country samples. ${ }^{\ddagger} p$-values of Chi-square tests of independence across generational groups. 
As shown in Table 2, overall greatest (either moderate or serious) concern was expressed about political and moral issues, rather than environmental or economic, with the top concerns being crime and violence (58\%), national politics (52\%) and breakdown of society's values (50\%). In contrast, only $44 \%$ expressed moderate or serious concern about long-term economic depression and climate change. Significant differences were found between countries in level of concern for 17 of the 23 issues, with Americans being more concerned on most. This was especially the case for political and economic issues, where US scores were about 20 percentage points higher than those for Australia or Canada.

Generally speaking, concern about societal issues increased with age, but differences were significant for only eight concerns (see Table 2). For some issues, the proportion of moderately or seriously concerned Pre-boomers was around 30 percentage points higher than Generation Y, especially on political issues such as the state of national politics (74\% compared to 43\%), political corruption (71\% compared to $41 \%$ ) and global politics (63\% compared to $36 \%$ ). Again, Pre-boomers were also more likely to report thinking about societal issues weekly or always, with $37 \%$ of Pre-boomers across all issues versus 32\% of Baby boomers, 30\% of Generation Y and 29\% of Generation X.

\subsection{Concern and stress}

No differences were found between countries in the numbers of respondents who reported perceived stress scores in the categories of very low, moderately low, moderately high and very high (see Appendix 1 for a more detailed description of the analysis). However, there was a generational difference in the degree of perceived stress with larger proportions of the younger generations (Generations $\mathrm{X}$ and $\mathrm{Y}$ ) reporting greater levels of stress than the older generations (Baby Boomers and Pre-boomers).

The perceived stress scores were also regressed onto independent variables that included factors derived from the personal and social concerns data, and generational membership. The factors drawn from the personal concerns data described the personal wellbeing, employment, financial, and relationship concerns of respondents. Factors of the societal concerns data also revealed broader factors of social, environmental and political concerns. These variables, along with generational membership were entered into a hierarchical regression, the order of which was determined by the relative strengths of the correlations of variables with perceived stress. The personal concerns were entered as Block 1, generational membership was entered as Block 2, and the societal concerns were entered last. A summary of results for each step of the hierarchical multiple regression is provided at Table 3. 
Table 3: Summary of hierarchical regression analysis for concern factors and generation variables as predictors of perceived stress

\begin{tabular}{|c|c|c|c|c|c|c|}
\hline & Variables & $B$ & $t$ & $R$ & $R^{2}$ & $\Delta R^{2}$ \\
\hline \multirow{5}{*}{ 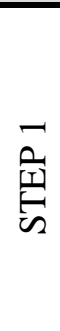 } & Constant & 18.324 & $42.988 * *$ & \multirow[t]{5}{*}{.514} & \multirow[t]{5}{*}{.264} & \multirow[t]{5}{*}{.264} \\
\hline & Personal F1 "Personal wellbeing" & 5.515 & $17.008 * *$ & & & \\
\hline & Personal F2 “Employment” & 1.154 & $5.736 * *$ & & & \\
\hline & Personal F3 "Financial" & -.425 & -1.414 & & & \\
\hline & Personal F4 "Relationships" & -1.091 & $-3.977 * *$ & & & \\
\hline \multirow{8}{*}{$\begin{array}{l}N \\
\frac{1}{\omega} \\
\text { I }\end{array}$} & Constant & 15.924 & $24.658 * *$ & \multirow[t]{8}{*}{.534} & \multirow[t]{8}{*}{.285} & \multirow[t]{8}{*}{.021} \\
\hline & Personal F1 "Personal wellbeing" & 5.399 & $16.802 * *$ & & & \\
\hline & Personal F2 “Employment” & .335 & 1.492 & & & \\
\hline & Personal F3 "Financial" & .066 & .213 & & & \\
\hline & Personal F4 "Relationships" & -1.087 & $-4.002 * *$ & & & \\
\hline & Generation Y & 4.463 & $6.753 * *$ & & & \\
\hline & Generation $\mathrm{X}$ & 2.889 & $4.597 * *$ & & & \\
\hline & Baby boomers & 1.463 & $2.420 *$ & & & \\
\hline \multirow{11}{*}{$\begin{array}{l}m \\
\text { 至 } \\
\text { v }\end{array}$} & Constant & 18.065 & $24.619 * *$ & \multirow[t]{11}{*}{.547} & \multirow[t]{11}{*}{.299} & \multirow[t]{11}{*}{.014} \\
\hline & Personal F1 "Personal wellbeing" & 5.736 & $17.510^{* *}$ & & & \\
\hline & Personal F2 “Employment” & .421 & 1.885 & & & \\
\hline & Personal F3 "Financial" & .313 & 1.014 & & & \\
\hline & Personal F4 "Relationships" & -.890 & $-3.282 * *$ & & & \\
\hline & Generation Y & 3.748 & $5.586 * *$ & & & \\
\hline & Generation X & 2.311 & $3.650 * *$ & & & \\
\hline & Baby boomers & 1.112 & 1.844 & & & \\
\hline & Societal F1 "Social" & -.694 & $-2.091 *$ & & & \\
\hline & Societal F2 "Environmental" & -.480 & -1.941 & & & \\
\hline & Societal F3 "Political" & -.206 & -.927 & & & \\
\hline
\end{tabular}

As can be seen in Table 3, step three reveals the "personal wellbeing" factor $(B=5.74)$ as a positive predictor of perceived stress, and the "relationships" factor $(B=-.89)$ as a negative predictor of perceived stress. Two of the three generation variables were significant predictors of perceived stress 
relative to the Pre-boomer reference category: Generation X and Generation $\mathrm{Y}(p<.001)$, while the "social" factor $(B=-.694)$ was also a significant but negative predictor.

In combination, all variables explained approximately $30 \%$ of the variance in perceived stress, which is considered to be a large effect (Cohen 1988). Most of this explained variance can be attributed to the personal concerns, with minor contributions from generational membership and societal concerns. The hierarchical regression identified that the variance in perceived stress associated with "personal wellbeing" and "relationships", as well as the Generation X and Generation Y variables, was not explainable in terms of the other variables. That the "personal wellbeing" and "relationships" factors did not change in the presence of the generation variables suggests that generational differences could not account for the relationships between "personal wellbeing" concerns and stress, and "relationships" concerns and stress.

\section{Discussion}

This study found relatively high levels of concern over a wide range of societal and personal issues: on average, around half (49\%) of respondents across the four countries were moderately or seriously concerned about personal matters, while four in ten $(41 \%)$ were moderately or seriously concerned about societal matters. Being focused on concerns, the study does not present a total picture of people's attitudes to life today. However, it adds a dimension, in terms of the number and specificity of issues covered and the tenor of the responses, which is not adequately captured by the commonly used objective measures of quality of life and progress, such as income, health and education, or other subjective measures such as life satisfaction and happiness, as discussed in the Introduction.

These implications for how we think about quality of life, progress and the future reinforce earlier work, as also noted in the Introduction. For example, Steenvoorden (2015, p. 86), in a conceptual and empirical study of "societal unease", argues it is "a latent concern among citizens in contemporary western countries about the precarious state of society". This concern arises from the "perceived unmanageable deterioration" of five fundamental aspects of society: distrust in human capability to make improvements and overcome problems, loss of ideology, decline of political power, decline of community, and socioeconomic vulnerability. Societal unease is only weakly related to happiness, showing that personal happiness is clearly distinct from societal unease.

Recent surveys have strengthened and updated the evidence on people's concern and discontent about their societies. Two global studies found that, overall, majorities of their citizens believed "the system" was not working, no longer served them, and favoured the rich and powerful (but with differences within and between developed and developing countries) (Edelman 2017; Ipsos MORI 2017). In one survey, a majorities in 14 of 22 countries said their country was in decline (Ipsos MORI 2017). Overall, more thought their generation had had a worse life than their parents, and youth today would have a worse life than their parents, than thought life was or would be better. In the other survey, two thirds of 28 countries were "distrusters", with, on average, less than $50 \%$ of people trusting the major institutions of government, business, media and NGOs; overall, more than three quarters agreed the system was biased against regular people and favoured the rich and powerful; and more than two thirds did not have confidence that current leaders could address their country's challenges (Edelman 2017). Corruption, globalization and technological change were weakening trust in global institutions; there was growing despair about the future, a lack of confidence in the possibility of a better life for one's family (Edelman 2017).

The findings can also be considered in the wider context of the global threats facing humanity and people's perception of the risk that our way of life will end, and even that humanity will be wiped out, within 100 years, as discussed in a companion paper based on other questions in this survey (Authors 2015). That study found that, across the four countries, $54 \%$ of respondents rated the risk of our way of life ending within the next 100 years at $50 \%$ or greater, and $24 \%$ rated the risk of humans being wiped out at $50 \%$ or greater. In response to six statements on how people respond to these perceived 
risks, almost $80 \%$ agreed "we need to transform our worldview and way of life if we are to create a better future for the world". Perceived risks to humanity were positively correlated with societal and personal concerns, and with stress.

The interesting findings that emerge from this study and that warrant further discussion fall into four areas: (1) the ranking of concerns, (2) country differences, (3) age differences, (4) the relationship between concerns and stress, and (5) the relevance of the findings to futures research.

\subsection{Ranking of concerns}

The findings are important in showing current social and political issues, not economic and environmental crises, top the list of people's societal concerns. These are the issues that are "closest to home" in terms of their current impact on people. (Climate change, which would probably be rated by scientists as the greatest global threat, is ranked tenth). This finding is consistent with other research which shows that our immediate, personal experiences count for more, psychologically, than abstract statistics and future uncertainties (Myers 2013). The findings are also consistent with other research that demonstrates the moral basis of people's concerns about quality of life and the future (Author 2000a; 2000b; 2005, pp.105-125). For example, an Australian survey on attitudes to the future included an open question that asked, "What do Australians need to do, either as individuals or as a nation, to manage change better and improve future prospects?" (Author 2000b). By far the most common responses (given by $42 \%$ of respondents) related to the need to change personal values and behaviour. This category was followed by the need for better government, mentioned by $29 \%$, improving the economy (22\%), better education (19\%) and protecting the environment (13\%).

\subsection{Country differences}

Americans were the most concerned on many of the societal issues, especially political and economic issues, where US scores were about 20 percentage points higher than those for Australia or Canada. The country differences in societal concerns are consistent with responses to other questions in this survey on perceptions of global threats to society and humanity, which showed that Americans rank these threats higher than the other three countries (although the differences are not great) (Authors 2015). The findings of this study could reflect several aspects of American society: weaker social welfare protection, a suspicion of government (especially federal), the US's dominant role in international affairs, including wars; and the effects of the 9/11 terrorist attacks and the global financial crisis. The findings also echo those of other studies, including one report that concluded the US was experiencing perhaps the longest period of pessimism in its history (Penn 2012). Americans believed their country was heading in the wrong direction, their generation was worse off than their parents' generation, and that their children would be still worse off, the report says. Furthermore, political corruption, too much focus on material things, and the influence of money in politics were weakening their values and standing in the world.

A recent US study found that Americans had since the 1970s become both more independent and more ideologically extreme, with the overall trend being towards more Americans identifying as Republican or conservative (Twenge et al. 2016). For example, more Millennials (or Gen Y) identified as conservative than either Gen X or Boomers did at the same age, and fewer were Democrats compared with Boomers when they were young. Such findings anticipated the election of Donald Trump as president of the US, with all that signifies for the future of the US and the world. The relative lack of significant country differences on personal concerns shows how these transcend national boundaries to reflect modernity more broadly (at least as it is experienced by the people of the four countries studied).

\subsection{Age differences}

The age differences in levels of concern are particularly interesting and potentially important. They show that societal concerns increase with age, but personal concerns decreased with age. The 
generational labels used in this study signify both different age groups and different generations. A cross-sectional survey such as this cannot distinguish between the two: that is, between age differences and generational (cohort) differences. Thus the results may reflect, for example, a tendency for Generation Y to be more self-focused as a normal part of their development (Twenge et al. 2015), for Generation $X$ to be more concerned than other generations with retirement prospects, or Generation Y, Generation X and Baby boomers to be more pre-occupied than Pre-boomers with issues such as the cost of the living and financial security rather than with broader societal issues.

However, the relatively linear gradients in levels of concern across age groups and the size of the differences - perhaps especially for "existential" issues such as emptiness, loneliness, failure, making wrong decisions and death - suggest that the differences could, at least to some degree, reflect generational changes. These changes could be the result of the individualism, sense of insecurity, uncertainty and risk, a lack of clear frames of reference that have increased over successive generations and which characterise late-modernity, as found in a study of changes in Finnish students' fears for the future between 1983 and 2007 (Lindfors et al. 2012). The study showed that fears about war, terrorism and environmental disasters fell, and those about work and education did not change substantially. However more personal fears rose, including fears of failure and making wrong choices, future family and partners, loneliness, accidents and, especially, health and death. The authors conclude that perceptions of risk have become more individualised, noting that adolescents' images of the future act as a mirror of the times, reflecting the values and ethos of society and its social and cultural norms and their changes over time. "Cultural and societal changes, including emphasis on individual choice and increased uncertainty, seem to create perceptions of uneasiness and insecurity in young people's transitions to adulthood" (Lindfors et al. 2012, p.998). Other research also contends that generational differences are real and useful in explaining differences among groups of people (Campbell et al. 2015), and that cultural change in the form of cohort and time period effects cannot be ignored as influences in cross-sectional and longitudinal studies (Twenge et al. 2017).

This study's findings, especially the higher concern among young people over relational and existential issues and their higher levels of stress are consistent with a new narrative that, contrary to the orthodox view that young people's wellbeing is continuing to improve in developed countries, it has declined over the past fifty years or more (Author 2011). According to this new story, the changed trajectory in their health is linked to a shift in importance from socio-economic determinants of health to cultural; from material deprivation to psychosocial deprivation. Mental illness has become more prevalent, and now accounts for by far the biggest share of the burden of disease among Western youth (Author 2011).

\subsection{Concerns and stress}

Personal and societal concerns were found to have a large effect on perceived stress. Personal concerns were by far the largest predictor of stress and explained $26 \%$ of the variance. Again, this is consistent with other research. In the Australian futures survey cited above, the $53 \%$ of respondents who were pessimistic about the future of humanity were asked if their concerns "in general diminish or reduce your enjoyment of life" (Author 2000b). Only 2\% said "very much" and 13\% "quite a lot", while $48 \%$ said "not much" and 35\% "not at all" (this means, nevertheless, that $63 \%$ of this group said they were personally affected). However, it is important to bear in mind that even personal concerns are themselves shaped by social conditions; they tell us something about the quality of life modern societies offer.

In line with the general pattern found in the personal concerns data, perceived stress was greater for younger than older generations. The prediction of perceived stress if respondents belonged to either Generation X or Generation Y contained significant contributions above that for the Pre-boomers, while the incremental difference in perceived stress, if respondents belonged to the Baby boomers generation, was not significant. These findings reinforce the argument that there is a psychological cost to setting and achieving life goals and confronting the complexities of modern life. 
Interestingly, the present study found specific concerns could have positive or negative correlations with perceived stress: i.e., greater concern was associated with greater stress with some issues, less stress with others. The concern factor most strongly predictive of perceived stress was "personal wellbeing", indicating that individuals who are more concerned about emotional issues (e.g. emptiness, loneliness, failure/disappointment) and health and aging (e.g. old age, death, mental/emotional health) are also more likely to report feeling stressed. Conversely, individuals concerned about "relationships" (e.g. with family and friends) are less likely to report feeling stressed. It is possible that this is because these concerns reflect being socially connected and having close personal relationships, which is crucial to wellbeing even if it can also cause worry. In other words, the difference is between isolation and belonging, between being concerned for oneself and concerned for others. This has a powerful bearing on people's wellbeing (Author 2005, pp. 59-104).

Alternatively, the negative association between relationship concerns and perceived stress might reflect a tendency to engage in avoidant behaviour which is a marker of poor psychological health and is often centred on personal relationships. For example, a strategy to minimise the emotional impact of relationship problems is to suppress conscious awareness of them, and hence fail to acknowledge the problems as real. Accordingly, although individuals who engage in this strategy might be aware of higher levels of perceived stress in an overall sense, they could also be unable to identify concerns with personal relationships as a source.

Similarly, individuals more concerned about issues in the "social" factor (e.g. the pace of change, terrorism, moral decline, crime and violence) are also likely to report lower levels of stress. This appears to run counter to the findings of the Australian futures survey mentioned above (although it asked about "enjoyment of life" not stress, which may not belong to different ends of the same continuum). It may be that those who worry about such issues are less pre-occupied with or concerned about personal issues, and more socially engaged, and so less stressed for that reason. This possibility might be age-related, as noted above; the oldest respondents may well have more time to reflect on social issues as the opportunities for many personal goals have passed, and accordingly these individuals are unlikely to be pre-occupied with them. The oldest members of society are also at a life stage that is characterised by concern for the wellbeing of future generations (Browning 2004). The lived experience of older people could also provide a lens through which social systems and issues bear on individual lives, knowledge which is reflected in the focus of their concerns. Nonetheless, these negative correlations between concern and stress are unexpected and deserve further investigation.

How individuals within particular population groups can improve their wellbeing in the light of these findings is difficult to specify, given that a survey of this kind captures many different sources of effect (current zeitgeist, stage of life, generational influence and culturally-specific factors). However, an obvious trend in modern life is the extent to which individuals are motivated by extrinsic values and consequently the degree of personal control they surrender to broader influences in determining what has meaning and is purposeful in their own lives. While it is acknowledged that modern life places demands on individuals that can be difficult to avoid, opportunities to pursue selfdetermination can lead to better psychological health and offer resilience against stressors (Deci \& Ryan 2008). These possibilities for improving wellbeing are speculative based on results of the present study. Further research which specifically examines individuals' opinions regarding the factors that would improve their own personal wellbeing, and whether these differ according to generation and/or country, would add to knowledge in this area.

\subsection{Relevance to futures research}

The study's findings on the levels of people's concerns on a wide range of issues, many futureoriented, their rankings, age differences and associations with psychological stress, contribute to futures research by elucidating the complex relationships that lie behind futures thinking and our ability to determine the future. Within the futures field, Slaughter (2002) has emphasised the importance of deeper approaches to futures studies that focus on qualities such as meanings, values, 
worldview commitments. "(I)t has become clear that our ability to understand the world 'out there' crucially depends on an underlying world of reference that is 'in here'." (p.493). Hideg and Novaky (2010) describe the construct of "future orientation" as a way of thinking "filled with preconceptions, imagination and expectations" (p.230). In two surveys in Hungary a decade apart, they explore people's attitudes to the future in terms of caring, trust, fear and influence. They conclude that, despite positive changes, "...Hungarian society has not yet learned to face changes, or learned to think in a future-oriented way, or to elaborate life strategies that work towards an acceptable, tenable future" (p.236).

In relation to the implications of this study's findings for futures research, having concerns - whether personal or societal - is not necessarily bad, despite the personal association with stress; it depends on people's sense of agency, their capacity to change their circumstances. Individually, concern could motivate people to change an unsatisfactory personal situation. Socially, high levels of concern could be a spur to right perceived wrongs, and so drive social change. However, if high levels of concern, whether personal or societal, reflect a sense of pessimism and demoralisation, a loss of vitality and confidence, this could erode not only people's own wellbeing, but their faith in society and its future, so reducing social cohesion and resilience. When individuals learn to view themselves and their environment in a particular way, this learning can bias what future information is attended to and constrain how the information is interpreted and acted upon. If, for example, individuals sense that they have limited agency to alter what they perceive as a fragmented and incoherent social world, this could accentuate the self-focus encouraged by an individualistic society, as suggested above and discussed in the companion paper, and weaken society's capacity to address global threats and challenges (Author 2010; Authors 2015).

Poor health and wellbeing, both physical and mental, affects people in many life roles - as students, workers, parents and citizens. These impacts are not only the result of clinically significant health problems (which, nonetheless, affect substantial segments of the population). High rates of illness, especially mental illness, also reflect public mood, morale and vitality more broadly. Not only does population wellbeing affect the ability of societies to withstand adversity, it can shape how they respond to it - whether in ways that make things better or worse (Eckersley, 2010). And this, in turn, further impacts on wellbeing.

This is not widely appreciated. A false dichotomy often characterises debate and discussion about national and international affairs. On one hand, these matters are seen as shaped by large, external forces such as economic development, technological change, environmental degradation and resource depletion, and war and conflict. Population health may be affected by these forces, but health itself is not usually seen as a contributor to larger-scale social developments. The perspectives of economics, politics and the environment dominate the discourse. On the other hand, considerations of health focus on internal, psychological and physiological processes and personal attributes, circumstances, behaviours and experiences. The dominant frame of reference is the biomedical model of health and wellbeing as an attribute or property of individuals.

Change in both the social and personal, external and internal, worlds is shaped by a complex interplay between them. Understanding this interplay is important to comprehending what is happening in both realms. In other words, human "subjectivity" plays an important part in the functioning of social systems; it is what most distinguishes them from other, biophysical systems.

\section{Conclusion}

This study of over 2,000 respondents in the US, UK, Canada and Australia has found people feel considerable concern over a range of personal and societal issues, and that these concerns are associated with perceived psychological stress. Americans were the most concerned about societal issues, especially political and economic, a finding that might have been reflected in the 2016 
presidential election. Young people, who best reflect contemporary society because they are growing up in it, were the least concerned about societal issues, but the most concerned about personal issues and the most stressed.

Taken together, the findings raise important questions about people's wellbeing and the health of Western societies that warrant more study. These include the intriguing differences in perspective and stress among generations that might reflect cohort differences resulting from sociocultural changes (not just age differences). That levels of concern could be either negatively or positively associated with stress, and why, also has implications for how life today is affecting people's wellbeing and health. Findings also highlight the trade-off between people's material and psychological realities and this tension should be acknowledged in any measurement of wellbeing. This holistic approach can better enable social development that facilitates future wellbeing.

Furthermore, findings pose questions for society as a whole and its capacity to manage change and improve prospects. They suggest researchers, policy-makers and leaders need to pay more attention to the internal, psychosocial dynamics of modern life and people's situation, not only to its external, biophysical and socio-economic dimensions. They also need to go beyond specific policy responses to embrace both broader and deeper social, moral and existential perspectives and responses. In these ways, the study contributes to what is arguably one of humanity's most difficult tasks: to mobilise people, politically and socially, to respond on the necessary scale to the threats and challenges confronting the world today. This is a core concern of futures research.

\section{References}

Browning, D. (2004) An ethical analysis of Erikson's concept of generativity, In The generative society: Caring for future generations. de St. Aubin, E., (Ed); McAdams, Dan P., (Ed); Kim, TaeChang, (Ed); pp. 241-255; Washington, DC, US: American Psychological Association. xiii, 292 pp. http://dx.doi.org/10.1037/10622-015

Campbell, W.K., Campbell, S.M., Siedor, L, \& Twenge, J.M. (2015) Generational changes are real and useful. Industrial and Organizational Psychology, 8, 1-8.

Cohen, J. (1988) Statistical power analysis for the behavioural sciences (2nd ed.). Hillsdale, NJ: Erlbaum.

Cohen, S., Kamarck, T., \& Mermelstein, R. (1983) A global measure of perceived stress. Journal of Health and Social Behaviour, 24, 385-396.

Deci, E.L., \& Ryan, R.M. (2008) Self-determination theory: A macrotheory of human motivation, development and health. Canadian Psychology, 49, 182-185.

Dolnicar, S., Laesser, C. \& Matus, K. (2009) Online versus paper format effects in tourism surveys. Journal of Travel Research, 47, 295-316.

Eckersley, R.M. (2000a) The mixed blessings of material progress: Diminishing returns in the pursuit of happiness. Journal of Happiness Studies, 1, 267-292.

Eckersley, R.M. (2000b) The state and fate of nations: Implications of subjective measures of personal and social quality of life. Social Indicators Research, 52, 3-27.

Eckersley, R.M. (2005). Well \& good: Morality, meaning and happiness, second ed. Melbourne: Text. Eckersley, R.M. (2009) Population measures of subjective wellbeing: How useful are they? Social Indicators Research, 94, 1-12. 
Eckersley, R.M. (2010). Population health: a forgotten dimension of social resilience. In S. Cork (Ed). Resilience and transformation: Preparing Australia for uncertain futures (pp. 115-120). Melbourne: CSIRO Publishing.

Eckersley, R.M. (2011) A new narrative of young people's health and wellbeing. Journal of Youth Studies, 14, 627-638.

Eckersley, R.M. (2016) Is the West really the best? Modernisation and the psychosocial dynamics of human progress and development. Oxford Development Studies, 44, 349-365.

Edelman Intelligence. (2017) Edelman Trust Barometer: 2017 annual global study. http://www.edelman.com/trust2017/. Accessed 28 April 2017.

Faul, F., Erdfelder, E., Lang, A.-G., \& Buchner, A. (2007). G*Power 3: A flexible statistical power analysis program for the social, behavioural, and biomedical sciences. Behaviour Research Methods, 39, 175-191.

Firth-Cozens, J. (2003) Doctors, their wellbeing, and their stress: It's time to be proactive about stress - and prevent it. British Medical Journal, 326, 670-671

Hideg, E., \& Novaky, E. (2010) Changing attitudes to the future in Hungary. Futures, 42, 230-236.

Ipsos Social Research Institute (2015) The top issues facing Australia. December 2014.

http://ipsos.com.au/wp-content/uploads/2015/02/Ipsos-Issues-Monitor-October-to-December-2014National.pdf. Accessed 22 November 2015.

Ipsos MORI. (2017) Global study shows potential for more political uncertainty ahead. https://www.ipsos-mori.com/researchpublications/researcharchive/3826/. Accessed 28 April 2017.

Lindfors, P., Solantaus, T., \& Rimpela, A. (2012) Fears for the future among Finnish adolescents in 1983-2007: From global concerns to ill health and loneliness. Journal of Adolescence, 35, 991-999.

Mackay, H. (1997) Generations: Baby boomers, their parents \& their children. Sydney: Pan Macmillan.

Myers D. (2013) Social psychology (11th ed.). North Ryde, NSW: McGraw Hill.

Penn, M. (2012). Americans are losing confidence in the nation but still believe in themselves. The Atlantic, 27 June. http://www.theatlantic.com/national/archive/2012/06/americans-are-losingconfidence-in-the-nation-but-still-believe-in-themselves/259039/. Accessed 18 March 2016.

Pew Research Center (2015) Public's policy priorities reflect changing conditions at home and abroad. http://www.people-press.org/2015/01/15/publics-policy-priorities-reflect-changingconditions-at-home-and-abroad/ Accessed 22 November 2015.

Randle, M. \& Eckersley, R. (2015) Public perceptions of future threats to humanity and appropriate societal responses: An international study. Futures, 72, 4-16.

Rowlands, I.J., Dobson, A.J., \& Mishra, G.D. (2015) Physical health of young, Australian women: A comparison of two national cohorts surveyed 17 years apart. Public Library of Science, DOI:

10.1371/journal.pone.0142088.

Sapolsky, R. (2005) Sick of poverty. Scientific American, December.

http://www.scientificamerican.com/article/sick-of-poverty/. Accessed 18 March 2016.

Slaughter, R.A. (2002) Beyond the mundane: Reconciling breadth and depth in futures enquiry. Futures, 34, 493-507. 
Steenvoorden, E.H. (2015) A general discontent disentangled: A conceptual and empirical framework for societal unease. Social indicators Research, 124, 85-110.

Survey Sampling International. (2016) SSI Capabilities. https://www.surveysampling.com/about/. Accessed 23 April 2016.

Twenge, J.M., Carter, N.T., \& Campbell, W.K. (2017) Age, time period, and birth cohort differences in self-esteem: Reexamining a cohort-sequential longitudinal study. Journal of Personality and Social Psychology. 112, e9.

Twenge, J.M., Honeycutt, N., Prislin, R., \& Sherman, R.A. (2016) More polarized but more independent: Political party identification and ideological self-categorization among US adults, college students, and late adolescents, 1970-2015. Personality and Social Psychology Bulletin. 0146167216660058 .

Twenge, J.M., Sherman, R.A., \& Lyubomirsky, S. (2015) More happiness for young people and less for mature adults: Time period differences in subjective wellbeing in the United States, 1972-2014. Journal of Psychological and Personality Science, DOI: 10.1177/1948550615602933.

Wiklund, M., Malmgren-Olsson, E-B, Ohman, A., Bergstrom, E., \& Fjellman-Wiklund, A. (2012) Subjective health complaints in older adolescents are related to perceived stress, anxiety and gender a cross-sectional school study in Northern Sweden, BMC Public Health, 12, 993.

Zagorski, K., Evans, M.D.R., Kelley, J., \& Piotrowska, K. (2014) Does national income inequality affect individuals' quality of life in Europe? Inequality, happiness, finances, and health. Social Indicators Research, 117, 1089-1110.

\section{Funding}

This work was supported by the Institute for Innovation in Business and Social Research at the University of Wollongong Australia. 


\section{Appendix 1}

Based on the distribution of perceived stress scores, the sample was split into four groups: "very low" (score 0-18, $\mathrm{n}=493$ ), "moderately low" (score 19-24, $\mathrm{n}=485$ ), "moderately high" (score 25-29, $\mathrm{n}=583$ ) and "very high" (score 30-56, $n=512$ ). Cross tabulations revealed no significant differences between countries in levels of stress $(p=0.171)$, however significant differences were found between generations. The majority of younger people (Generations $\mathrm{Y}$ and $\mathrm{X}$ ) fell into the very high and moderately high perceived stress categories ( $71 \%$ and $55 \%$ respectively), whilst a minority of the older generations fell into these two categories (41\% of Baby boomers and $26 \%$ of Pre-boomers). Conversely, Pre-boomers had by far the largest proportion with very low stress (45\%), with $32 \%$ of Baby boomers, $23 \%$ of Generation X and only $11 \%$ of Generation Y reporting similarly low levels.

Multiple regression analysis was performed to identify whether certain types of concerns predicted perceived stress. First, to investigate the underlying structure of the concern items and to reduce the large number of issues to a manageable number of independent variables in the regression model, factor analyses were performed for personal concerns and societal concerns. Data from 2,073 participants was subjected to principal axis factoring with Varimax rotation and four factors (with Eigenvalues exceeding 1) were identified as underlying the 19 personal concerns (accounting for $55.6 \%$ of the variance). Factor one includes concerns relating to emotions, ageing and health, and was labelled "personal wellbeing". Factor two includes concerns relating to employment and education and has been labelled "employment". Factor 3 relates to financial security and retirement and has therefore been labelled "financial", and Factor 4 includes concerns related to family and friends and has been labelled "relationships".

Three factors (with Eigenvalues exceeding 1) were identified as underlying the 23 societal concerns. In total, these factors accounted for $56.1 \%$ of the variance in the data. Factor 1 includes a broad range of concerns relating to various social and global issues, and has therefore been labelled "social". Factor two is characterised by environmental issues and has been labelled "environmental", and Factor 3 includes political and economic issues, and has been labelled "political".

Next, the nature of the relationships between perceived stress, generations and the identified personal and societal factors were investigated by calculating bivariate Pearson's correlation coefficients. Medium to large size positive correlations (Cohen 1988) were found between perceived stress and the four personal concern factors: "personal" $(r=.498)$; "employment" $(r=.362)$; "financial" $(r=.323)$ and "relationships" ( $r=.292)$, as well as generation ( $r=.277)$. Significant but small positive correlations were found between perceived stress and two of the societal factors: "social" $(r=.113)$ and "environment" $(r=.061)$. The correlation between perceived stress and the societal factor "political" was not significant.

Finally, to estimate the proportion of variance in perceived stress that can be accounted for by societal and personal concerns and generation, hierarchical regression analysis was conducted. The four personal factors and three societal factors were entered as independent variables with perceived stress as the dependent variable. Based on the differences identified between generations in perceived stress this variable was also included in the model, but recoded to create new binary variables for Baby

\footnotetext{
${ }^{1}$ One way ANOVAs examining differences in these seven factors by country of respondent demonstrated that the factors captured variation between countries in a manner reflecting the by-item analysis reported earlier (see Tables 1 and 2). Namely, differences in concern over (i) finance and retirement were driven by differences in factors scores between Australian and North American respondents; (ii) social and political issues by differences in scores of USA respondents with others and (iii) environmental issues by differences in scores between UK and North American respondents. 
boomers, Generation X and Generation Y. Pre-boomers were the reference category, therefore differences between Pre-boomers and the other generations are indicated by the coefficients. Country of origin was not entered into the model due to the lack of association with perceived stress identified in previous analyses. All assumptions for multiple regression analysis were evaluated and met by the data. Personal concern factors were entered as block one as they were the most strongly correlated with perceived stress. Generation was entered as block two as it was next most highly correlated with perceived stress, and the three societal concern factors were entered as block three as they were least correlated with perceived stress. ${ }^{2}$

On step one, personal concerns factors accounted for a significant $26 \%$ of the variance in perceived stress, $R^{2}=.264, F(4,2068)=185.39, p<.001$. On step 2 , generations accounted for an additional $2 \%$ of the variance, $\Delta R^{2}=.021, \Delta F(3,2065)=20.57, p<.001$, and on step 3, societal concerns factors accounted for an additional $1 \%$ of the variance, $\Delta R^{2}=.014, \Delta F(3,2062)=13.66, p<.001$. In combination, the 10 predictor variables explained $30 \%$ of the variance in perceived stress, $R^{2}=.299$, $F(3,2062)=88.05, p<.001$. A combined effect of this magnitude is considered "large" (Cohen 1988).

\footnotetext{
${ }^{2}$ It could be argued that weighting variables by country population would yield greater representation in the analysis, however we resisted this approach as while it would produce an idealised international perspective, it would also fail to capture the impact that national borders have on the concerns of citizens within any one country, and associated variability across countries. The international perspective, particularly one that is increasingly being influenced by nationalism and national approaches to enduring problems like climate change and conflict, is more accurately depicted by a composite of profiles of individuals reflecting individual nation states. Second, to check that country of respondent did not reliably explain additional variance in perceived stress after the other aforementioned variables had been considered, a second regression entering country of respondent as a fourth block was performed. This demonstrated that the explicit inclusion of country of respondent added nothing to the reported model, $F(3,2059)=0.72, p=.543$.
} 